\title{
Development of shrimp-based chitosan film and assessment of its mechanical, barrier and antimicrobial properties
}

\author{
Jagruti Jankar ${ }^{1, *}$, Yogesh Nagargoje ${ }^{2}$, Yogita Chavan ${ }^{1}$, Jaydevi Jankar ${ }^{3}$, and Akshay Kumar Sahoo ${ }^{2}$ \\ 1 MIT College of Food Technology, MIT ADT University, Pune, India \\ 2 Department of Technology, Shivaji University, Kolhapur, India \\ ${ }^{3}$ Asian College of Arts and Science, Pune University, India.
}

\begin{abstract}
You Utilization of biodegradable films is a need of food packaging industries in order to reduce the hazards related to plastic use and to extend the food's shelf life. Various polysaccharides are in use for the purpose of making the films. In this research, chitosan based films were developed and its mechanical, barrier and antimicrobial properties were checked to fulfill the packaging requirements. Chitosan was extracted from shrimp waste and films were produced using 0.5-2 per cent concentrations. At ambient temperature, specific characteristics such as mechanical, barrier, and antimicrobial analysis were performed at an interval of two days. Among all, the films with 2 per cent chitosan showed best results in terms of tensile strength, thickness and percent elongation. Also, the films exhibited maximum resistance to water vapor permeability. The extracted chitosan at 2 per cent concentration had shown the maximum resistance against Staphylococcus aureus and Pseudomonas aeruginosa. From the current investigation it can be said that films with 2 per cent chitosan could be used as biodegradable food packing materials and can serve as material which would maintain a good city and future of world by minimizing plastic hazards..
\end{abstract}

\section{Introduction}

Plastic is used for various purpose in food sector such as food packaging in the form of plastic films, bags, trays, etc. been used for several years, but one should be aware of the toxic effects of plastics on human as well as on the environment. It results awfully, not only on nature but also on health of living beings. Soil pollution, water pollution, and air pollution are the worst effects of plastics. Moreover plastic is a vehicle for various diseases like cancer, headache, lung problems, heart disease, skin disorders, etc. These are caused by the harmful gases released after burning the plastics. Plastic packaging materials are typically made from synthetic products that are non-renewable and non-biodegradable. Because of the increasing demand for plastic use, particularly in the food packaging industry, plastics are largely manufactured in line with human population growth(13). The non-biodegradable feature of petroleum-based plastic products renders plastics improperly disposed of, leaving an enormous amount of unrecyclable and untreated plastic trash to pollute the earth. To compensate these severe problems, there is a need for such a technique which will not be causing any pollution and will protect the food quality and human health too. The use of films and edible coatings which degrade naturally can be a solution to these types of glitches. These films are obtained from different nature based polymers like polysaccharides and they can be developed from renewable sources (7). Significant progress has recently been made in the manufacturing of biodegradable plastics, primarily from renewable sources, for the creation of biodegradable products of comparable versatility to harmful plastics. It is expected that use of biodegradable plastic would lead to recycling and increasing the environmental impact associated with the processing oil based polymer (18). However, chitosan is a bio-based polymer derived from deacetylation of chitin from crustacean shells (1) have been used to as packaging aid for different food commodities. Also, it is a polycationic polymer which is soluble in diluted acids owing to protonation of amino groups. The characteristics of this polysaccharide such as biocompatibility, biodegradability and non-toxicity allow its use in the food industries, pharmaceutical and cosmetics. Development of chitosan edible films and packaging materials has been broadly studied at laboratory scale (4). Due to its film forming capacity and good mechanical properties, chitosan is an excellent source for films, edible coatings and can form transparent films that can meet various packaging needs (19). The present research was intended to develop edible films from different chitosan concentration and to evaluate its versatile properties for further use. The present investigation entitled "Development of chitosan based biodegradable films" was carried out in laboratory of Department of Technology (Food technology), Shivaji University, Kolhapur during 2015-16. Shrimp waste was collected from the local market of Kolhapur. It was originated from sea water of Ratnagiri, Maharashtra. The species found was Penaus Monodon.

\section{Materials and Methods}

*Corresponding author: jankjagruti@gmail.com 
The present investigation entitled "Development of chitosan based biodegradable films" was carried out in laboratory of Department of Technology (Food technology), Shivaji University, Kolhapur during 201516. Shrimp waste was collected from the local market of Kolhapur. It was originated from sea water of Ratnagiri, Maharashtra. The species found was Penaus Monodon.

\subsection{Chitosan extraction from shrimp waste}

Chitosan extraction for further study was carried out (14). Collected shrimp shells were washed with clean water to remove the unwanted parts on the surface, then it was subjected to drying and grinding into fine powder. The fine powder was soaked into $4 \%$ hydrochloric acid for $36 \mathrm{hrs}$ at room temperature for demineralization. It was then deproteinized using $5 \%$ sodium hydroxide at $90^{\circ} \mathrm{C}$ for $24 \mathrm{hrs}$. The process followed by deacetylation using $40-70 \%$ sodium hydroxide for $72 \mathrm{hrs}$ to give higher degree of deacetylation. The complete process flowchart of extraction was given in fig. 1 .

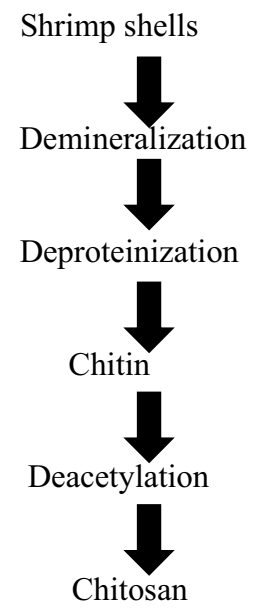

Fig.1 Extraction of chitosan

\subsection{Preparation of Films}

Films were prepared as reported by a specific method (5). Acetic acid was selected for making a film with $1 \%$ concentration. $1 \%$ acetic acid was used to dissolve different concentrations of chitosan viz. $0.5,1,1.5$ and 2 per cent. Glycerol at the concentration of $0.5 \%$ was added as a plasticizer and stirring was continued for 2-3 hrs until the complete homogenization of the mixture was obtained. Subsequently, after filtration the solutions were poured onto petri dishes and dried in a hot air oven at $80^{\circ} \mathrm{C}$ for $8 \mathrm{hrs}$. After drying, all films were kept at $25^{\circ} \mathrm{C}$ in a controlled environment chamber and $50 \%$ relative humidity was maintained.

\subsection{Mechanical and barrier testing of chitosan- based films}

Physical and mechanical testing of chitosan-based films was carried out as earlier reported (5).

\subsubsection{Thickness of the film}

The strips of films with the dimension of $2 \mathrm{~cm} \times 5 \mathrm{~cm}$ were taken to measure the thickness using micrometer (103-131, Mitutoyo, Japan). Random measurements at three different points were taken to calculate the mean value and further used for per cent elongation, puncture strength and tensile strength evaluation.

\subsubsection{Tensile strength}

Tensile strength was determined mechanically using a texture analyzer (TA.HD Plus, Stable Micro System). For the measurement of tensile strength and per cent elongation at break, standard method given by American society of testing and materials (ASTM) was followed.

\subsubsection{Puncture strength and per cent elongation}

Assessment of puncture strength and per cent elongation was carried out using the above mentioned texture analyzer. Strips of $2 \mathrm{~cm}$ were taken for analysis and cylindrical probe of $2 \mathrm{~mm}$ diameter was passed through the strips at steady speed of $1 \mathrm{~mm} / \mathrm{s}$.

\subsubsection{Water Vapor Transmission Rate}

The water vapor transmission rate (WVTR) of chitosan based films was analyzed by round cups with $100 \mathrm{ml}$ volume capacity and mouth area of $120 \mathrm{~cm}^{2}$. The cup was filled with $60 \mathrm{ml}$ water and covered with chitosan film tightly using adhesive tape and it was put into desiccator by maintaining $90 \%$ relative humidity using sulphuric acid The loss of water from the cup was observed with time and WVTR was evaluated.

\subsection{Antimicrobial Test}

Antimicrobial analysis was done by following the protocol revious protocol (16). Agar well diffusion method measures the antimicrobial activity which includes swabbing of nutrient agar plates with broth culture of Staphylococcus aureus and Pseudomonas aeruginosa. In each of these plated wells of $10 \mathrm{~mm}$ diameter and $2 \mathrm{~cm}$ apart were made using sterile cork borer. The solution of chitosan stored as stock solution at the concentration of $0.5-2 \mathrm{mg} / \mathrm{ml}$ in acetic acid were added into each well and kept at $4{ }^{\circ} \mathrm{C}$ for $10 \mathrm{~min}$ for diffusion. The plates were transferred to incubator at 
$37^{\circ} \mathrm{C}$ for 24 hours. The diameter of zone of inhibition was measured after incubation with four replications and the mean value was used calculated.

\subsection{Statistical Analysis}

The complete randomized design was used to evaluate the proficiency of films. The SAAS software was used for statistical analysis.

\section{Results and Discussions}

Extraction of chitosan was performed in accordance with 2.1 procedure. Chitosan extraction was confirmed by dissolving $0.5-2 \%$ chitosan in $1 \%$ acetic acid. Using casting techniques films were made from the $0.5-2 \%$ chitosan and examined for different properties.

\subsection{Mechanical and barrier properties of chitosan based films}

Table 1. Mechanical and barrier properties of different chitosan concentrations

\begin{tabular}{|c|c|c|c|c|c|}
\hline $\begin{array}{l}\text { Conc } \\
\text { entrat } \\
\text { ion of } \\
\text { chitos } \\
\text { an (g) }\end{array}$ & $\begin{array}{l}\text { Ten } \\
\text { sile } \\
\text { str } \\
\text { eng } \\
\text { th } \\
(\mathrm{M} \\
\mathrm{Pa})\end{array}$ & $\begin{array}{l}\text { Elon } \\
\text { gati } \\
\text { on } \\
(\%)\end{array}$ & $\begin{array}{l}\text { Pun } \\
\text { ctur } \\
e \\
\text { Str } \\
\text { eng } \\
\text { th } \\
\text { (N) }\end{array}$ & $\begin{array}{l}\text { WV } \\
\text { TR } \\
(\mathrm{g} / \mathrm{m} \\
{ }^{2} / \mathrm{da} \\
\mathrm{y})\end{array}$ & \begin{tabular}{|l} 
Thic \\
kne \\
ss \\
$(\mathrm{mm}$ \\
)
\end{tabular} \\
\hline 0.5 & $\begin{array}{l}26.2 \\
4^{\mathrm{a}} \\
28.0 \\
8^{\mathrm{b}} \\
\end{array}$ & \begin{tabular}{|ll}
13.89 & \\
& $\mathrm{c}$ \\
17.98 & \\
\end{tabular} & $\begin{array}{l}\mathrm{c}^{\mathrm{c}} \\
1.06^{\mathrm{b}} \\
1.13^{\mathrm{b}} \\
\mathrm{c}\end{array}$ & $\beta^{\mathrm{a}^{\mathrm{a}}} 108.1$ & 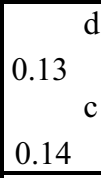 \\
\hline 1.5 & $\begin{array}{l}30.6 \\
\mathrm{c}\end{array}$ & $22.42^{b}$ & $\begin{array}{ll} & b \\
1.34 & \\
\end{array}$ & $\mathrm{sc}^{101.2}$ & $0.15^{\mathrm{b}}$ \\
\hline 2 & $\begin{array}{l}32.2 \\
6^{\mathrm{d}} \\
\end{array}$ & $37.85^{\mathrm{a}}$ & $1.77^{a}$ & $95.78^{d}$ & $0.16^{\mathrm{a}}$ \\
\hline L.S.D. & $\begin{array}{l}0.49 \\
59\end{array}$ & 0.8266 & $\begin{array}{l}0.232 \\
7\end{array}$ & 0.822 & 0.384 \\
\hline
\end{tabular}

Note: In the above table, the Average values of all properties were taken.

From the above table, it can be seen that chitosan films with $2 \%$ concentration gave a stronger film as compared to other concentrations. It had the highest tensile strength i.e.32.26 MPa which showed that it increased with chitosan concentration. Obtained results were in line with (3) the researchers who found that the tensile strength of film increases with concentration of chitosan. Besides, same results were revealed (2) who produced the films by the composition of chitosan, fish gelatin and microbial transglutaminase (MTgase).
They said that the concentration of chitosan increases, tensile strength of films also increases suggests that film thickness increases with chitosan concentration. Moreover, it can be depicted that films with $2 \%$ chitosan had good resistance to water vapor permeability. The results were resembled with the previous data (12) in which the chitosan films showed magnificent barrier properties to water vapor permeability. A film with $2 \%$ chitosan showed elongation of $38.25 \%$ and required maximum force of $1.606 \mathrm{~N}$ to puncture the film. It means that the \% elongation and puncture strength of the film also increases as the concentration of chitosan in the film increases. The results are in agreement with (15) who developed starch -chitosan composite films and found that the elongation at break was increased as chitosan concentration increased. In addition, (21) it was concluded that, the film which was prepared from $2 \%$ chitosan concentration had higher thickness, \% elongation and puncture strength, exhibited maximum resistance to water vapor permeability as well. The similar results were provided by (6) and (11) who intimated that high molecular weight chitosan films possess higher tensile strength and better barrier properties than low molecular weight chitosan films. Moreover, it can be depicted that films with $2 \%$ chitosan had good resistance to water vapor permeability. The results were resembled with the previous data reported by (12), the chitosan films showed magnificent barrier properties to water vapor permeability. A film with $2 \%$ chitosan showed elongation of $38.25 \%$ and required maximum force of $1.606 \mathrm{~N}$ to puncture the film. It means that the $\%$ elongation and puncture strength of the film also increases as the concentration of chitosan in the film increases.

\subsection{Antimicrobial activity of chitosan}

Experimental studies showed that tested concentration of extracted chitosan was antagonistic to gram positive bacteria Staphylococcus aureus and gram negative bacteria Pseudomonas aeruginosa. Four different concentrations $(0.5,1,1.5, \& 2 \%)$ of chitosan film were tested against the said bacteria and observed maximum inhibition at $2 \%$ concentration of chitosan. According to Goy et al.,(2016) 1\% chitosan showed inhibitory effect against S.aureus. The reason behind the antimicrobial activity of chitosan was owing to charged group in the backbone of polymer and their ionic interactions with components present in cell was eliciting the discharge of intracellular electrolytes and bring about microbe's death. Antifungal and antibacterial properties of chitosan have been already reported ([8]), [9],[17]). The microbes showed maximum resistance at $2 \%$ chitosan at which it showed maximum zone of inhibition (Fig.2). 


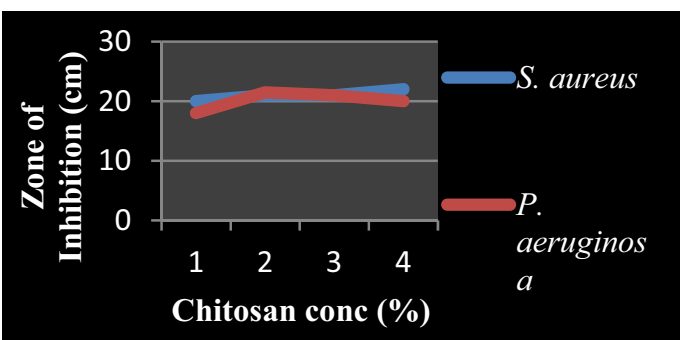

Fig.2. Antimicrobial activity of different concentrations of chitosan

\section{Conclusion}

Chitosan based films were developed by using different concentrations of chitosan (0.5-2\%). The extracted chitosan was examined for antimicrobial prperties and the films for mechanical and barrier properties. There was significant difference in the films made from each concentration and found the best results with $2 \%$ chitosan. Extracted chitosan showed antagonistic property against Staphylococcus aureus and Pseudomonas aeruginosa. In addition the $2 \%$ chitosan films exhibited maximum resistance to water vapor permeability. Therefore, the present investigation put forth an approach to use the chitosan films from shrimp waste as a packaging material in replacement of plastic with the view of avoiding the environmental pollution and extend the food's shelf life.

\section{Reference}

1. M. Aider LWT-Food Science and Technolgy 43, 837-842,(2010).

2. S .Alvarado, G. Sandoval, I. Palos, S. Tellez, Y. Aguirre-Loredo and G.Velazquez, Food Science and Technology, 35(4), 690-695(2015)

3. J. Bonilla, A. Talon, Emma , L. Atares, M. Vargas and A. Chiralt A, Journal of Food Engineering. 11, 271-278 (2013)

4. M. Cerqueira, B. Souza, J. Teixeira,A. Vicente, Food Hydrocolloids 27,175184(2012)

5. K. Chaturbhuj, S. Gupta, J. Bahadur, S. Mazumder , P. Variyar , A. Sharma Carbohydrate Polymers, 98,1610-1617. (2013)

6. R.H. Chen, and H.D. Hwa, Carbohydrate Polymers, 29, 353-358(1996)

7. Dai, H., Chang, P. R., Yu, J., and Ma, X.,Starch. 60(12),676-684(2008)

8. R.K. Dhall, Critical Review in Food Science \& Nutrition, 53, 435-450(2013)

9. M.Z. Elsabee, and E.S. Abdou, Materials Science and Engineering: C, 33(4), 1819-1841(2013)

10. R.C.Goy , S.T.B. Morais, and O.B.G. Assis, Revista Brasileira de Farmacognosia, 26(1), 122- 127(2016)
11. K.T. Hwang, J.T. Kim, S.T. Jung, G.S. Cho and H.J. Park Journal of Applied Polymer Science, 89(13), 34763484(2003)

12. I. Leceta, P. Guerrero, I. Ibarburu, M. Duenas and C.K. De la, Journal of Food Engineering, 116, 889-899 (2013)

13. M.Z.I. Mollah, N. Akter, F.B. Quader , S. Sultana and R.A. Khan, Open Journals of Organic Polymer Materials, 6,11-24 (2016)

14. Y.S. Puvvada, S. Vankayalapati and S. Sukhavasi, International Current Pharmaceutical Journal, 1(9), 258263(2012)

15. L. Ren, X. Yan, J. Zhou, J. Tong and X. $\mathrm{Su}$, International Journal of Biological Macromolecules, 105, 1636-1643(2017)

16. N. T. Sena , B.J. Gomes, M. E. Vianna, V.B. Berber, A.A. Zaia and C. C. Ferraz, Int Endod J;39,878-85( 2006)

17. R. A. Sheikh, M. A. Malik, S. A. AlThabaiti and M. A. Shiekh, Food Science and Technology Research, 19(2), 139- 155(2013)

18. J. H. Song, R. J. Murphy, R. Narayan and G. B. Davies, Biol Sci,364(1526),21272139(2009)

19. P. C. Srinivasa Ph.D. Thesis, CFTRI, Mysore (2004)

20. T. N. Van, T. Hanh and P. Thien $P$ The Open Biomaterials Journal, 4, 1-5(2013)

21. Y. X. Xu, , K. M. Kim, M. A. Hanna and D. Nag, Industrial Crops and Products 21(2), 185-192(2005) 